\title{
Regulation of Glycogen Metabolism and Glycogen Phosphorylase in Physarum polycephalum
}

\author{
By WERNER F. NADER† AND JÖRN-ULLRICH BECKER* \\ Botanical Institute, University of Bonn, Kirschallee 1, D-5300 Bonn 1, F.R.G.
}

(Received 12 November 1982)

\begin{abstract}
Glycogen and glycogen phosphorylase content of microplasmodia from Physarum polycephalum were studied during carbohydrate-limited growth and spherulation, induced by starvation. The results indicate that glycogen metabolism in this organism responds most strongly to the availability of external glucose. Glycogen phosphorylase is a constitutive enzyme, present with the same specific molecular activity at all phases of growth and during transition to spherules, supporting the observation that the enzyme cannot be regulated covalently by phosphorylationdephosphorylation. The enzyme is regulated only by metabolites, in a rather inefficient way: even during net synthesis of glycogen its degradation is not entirely stopped, resulting in a futile cycle. Its activity is merely slowed down to approximately $30 \%$ of its rate during glycogen breakdown after consumption of glucose. At this time, part of the glycogen, broken down, is apparently used for the synthesis of slime.
\end{abstract}

\section{INTRODUCTION}

Rapidly growing macro- and microplasmodia of the acellular slime mould Physarum polycephalum contain large amounts of glycogen. Very little is known about its metabolism in this model organism for the study of cell cycle and differentiation (Goodman, 1980). In the cellular slime mould Dictyostelium discoideum, glycogen metabolism is coupled to differentiation (Wright \& Park, 1975) and in Escherichia coli and yeast, to environmental factors (Chen \& Segel, 1968 a; Becker et al., 1982).

The activity of one of the key enzymes for glycogen breakdown, glycogen phosphorylase (EC 2.4.1.1), is modulated in these organisms by a wide variety of allosteric mechanisms, by induction and repression or even by covalent modification (Thomas \& Wright, 1976a, $b$; Chen \& Segel, 1968b; Fosset et al., 1971; Becker, 1982). Glycogen phosphorylase of Physarum polycephalum has been purified in this laboratory and its regulatory properties studied in vitro (Nader \& Becker, 1979). It seemed important to investigate which of the properties deduced from experiments in vitro are important in vivo. In this paper we present data concerning glycogen metabolism and phosphorylase activities and concentrations in Physarum polycephalum plasmodia under different external conditions.

\section{METHODS}

Materials. PD-10 columns with Sephadex G-25 were obtained from Pharmacia, $[\mathrm{U}-1+\mathrm{C}] \mathrm{glucose}$ from Amersham, and the nonionic detergent Chemulsol NPT 12 from S.A. Melle-Bezons, Neuilly, France. All enzymes and substrates were purchased from Boehringer. The chemicals, of analytical grade, were supplied by Merck and agarose (low EEO) for immunoelectrophoresis by Sigma.

Culture conditions. Microplasmodia of strain $\mathrm{M}_{3} \mathrm{CIV}$ from Physarum polycephalum were cultivated in $20 \mathrm{ml}$ semi-defined medium (axenic medium) (Daniel \& Baldwin, 1964) in $500 \mathrm{ml}$ Erlenmeyer flasks on a rotary shaker at 300 r.p.m. and $23^{\circ} \mathrm{C}$ in the dark. Cultures were maintained by transferring $2 \mathrm{ml}$ plasmodial suspension into

† Present address: Forstbotanisches Institut der Universität, Büsgenweg 2, 3400 Göttingen-Weende, F.R.G.

† Present address: Kettelhack Riker Pharma GmbH, Wilbecke 12-14, D-4280 Borken, F.R.G. 
fresh medium every second day (Hüttermann, 1972). For transfer into new medium, e.g. for spherulation (Daniel \& Baldwin, 1964), plasmodia were centrifuged at $500 \mathrm{~g}$ for $2 \mathrm{~min}$ and washed twice with the new medium.

Determination of protein and glycogen. The yellow pigment of the plasmodia was extracted with a mixture of $65 \%$ $(\mathrm{v} / \mathrm{v})$ acetone and $5 \%(\mathrm{w} / \mathrm{v}) \mathrm{TCA}$. Plasmodia were then dissolved in $0.4 \mathrm{M}-\mathrm{NaOH}$ at $60{ }^{\circ} \mathrm{C}$. Protein was determined by the Lowry method using bovine serum albumin as a standard. The rest of the sample was heated for $1 \mathrm{~h}$ in a boiling water bath and adjusted to $\mathrm{pH} 4.8$ with acetic acid. Glycogen was hydrolysed by amyloglucosidase (EC 3.2.1.3;1.4 $\mathrm{U} \mathrm{ml}^{-1}$ ) at $37^{\circ} \mathrm{C}$ for $2 \mathrm{~h}$. The liberated glucose was determined by hexokinase (EC 2.7.1.1) and glucose-6-phosphate dehydrogenase (EC 1.1.1.49) (Bergmeyer, 1974).

Determination of radioactively labelled glycogen. Plasmodia were first extracted in acetone/TCA as before. They were then dissolved by heating in $2.5 \mathrm{M}-\mathrm{KOH}$, and $1.5 \mathrm{vol} .96 \%(\mathrm{v} / \mathrm{v})$ ethanol containing $0.15 \mathrm{M}$-ammonium acetate was added to precipitate the glycogen. This solution was heated to boiling, centrifuged and the pellet was

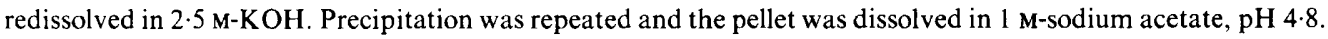
The solution was adjusted to $\mathrm{pH} 4.8$ and amyloglucosidase was added to hydrolyse the glycogen. The liberated glucose was determined enzymically. The ethanol precipitation was repeated and the supernatant was evaporated at $50{ }^{\circ} \mathrm{C}$. The residue was dissolved in $4 \mathrm{M}-\mathrm{HCl}$ and its radioactivity was determined by scintillation counting. Control experiments showed no loss of glycogen during acetone/TCA extraction and ethanol precipitation. After incubation at $\mathrm{pH} 4.8$ without amyloglucosidase, only $5 \%$ of the radioactivity was solubilized compared to the sample containing the glucosidase. The concentration of the radioactive glycogen was calculated from the specific radioactivity of the $\left[\mathrm{U}^{-14} \mathrm{C}\right]$ glucose $\left(1.2 \times 10^{4}\right.$ c.p.m. $\left.\mu \mathrm{mol}^{-1}\right)$.

Preparation of enzyme extracts and assay of glycogen phosphorylase. Enzyme extracts were prepared by sonication as described by Hoffmann \& Hüttermann (1975). If sonication-resistant spherules were visible in the culture, plasmodia and spherules were homogenized with the French pressure cell (Aminco, Silver Springs, Md., U.S.A.) at $8 \mathrm{t}$ pressure. After ultracentrifugation at $100000 \mathrm{~g}$, extracts were desalted by gel filtration (PD-10 columns) in $50 \mathrm{~mm}$-sodium citrate buffer, $\mathrm{pH} \mathrm{6.7.} \mathrm{Phosphorylase} \mathrm{activity} \mathrm{was} \mathrm{measured} \mathrm{as} \mathrm{previously} \mathrm{described} \mathrm{(Nader} \mathrm{\&}$ Becker, 1979) and expressed as $\mu \mathrm{mol}$ glucose 1-phosphate formed $\mathrm{min}^{-1}$.

Immunoelectrophoresis. The crude extracts were transferred into $50 \mathrm{~mm}$-ammonium carbamate by gel filtration (PD-10 columns), concentrated by lyophilization and dissolved to give a protein content of $18 \mathrm{mg} \mathrm{ml}^{-1}$. These samples were analysed by rocket immunoelectrophoresis (Laurell, 1966). The $1 \%$ agarose slab gels contained $200 \mu \mathrm{l}$ crude, desalted antiserum per $15 \mathrm{ml}$. Antiserum production was described by Nader (1980); its monospecificity was tested by two-dimensional immunoelectrophoresis (Laurell, 1966).

Determination of viscosity. Viscosity was estimated by the time taken (in seconds) for $0.1 \mathrm{ml}$ culture medium to run through a $0 \cdot 1 \mathrm{ml}$ enzyme pipette (Blaubrand, Brand, Wertheim, F.R.G.). No calibration of this method was attempted. An identical pipette was used for all experiments.

\section{RESULTS}

\section{Glycogen metabolism during growth and spherulation}

Drastic changes in glycogen concentration have been reported during growth of microplasmodia and at spherulation (McCormick et al., 1970). Therefore, phosphorylase activity and the kinetics of glycogen synthesis and breakdown were measured during growth of microplasmodia with glucose as carbon source (Fig. 1). Protein content doubled within $17 \mathrm{~h}$ (Fig. 1a) and increased further after depletion of glucose because the medium contained an excess of tryptone. Glycogen content, on the other hand, changed according to the availability of glucose, which was exhausted after $60 \mathrm{~h}$. Initially glycogen content doubled in $12 \mathrm{~h}$ (Fig. $1 \mathrm{a}$ ) (slightly faster than the increase of protein), but it was degraded immediately after all the glucose had been consumed. This was followed by a strong increase in viscosity (Fig. $1 b$ ), which indicates slime excretion. After $100 \mathrm{~h}$, protein accumulation ceased, and spherules became visible after $110 \mathrm{~h}$. Spherulation could be induced more synchronously by transferring plasmodia, grown in axenic medium for $48 \mathrm{~h}$, into minimal medium. Glycogen decreased immediately after the transfer and slime accumulated simultaneously (Fig. 2). The first spherules became visible $34 \mathrm{~h}$ later.

\section{Activity and concentration of glycogen phosphorylase during growth and spherulation}

The specific activity of glucose phosphorylase was measured during growth and spherulation in order to detect whether changes in glycogen concentration are due to changes in phosphorylase activity. As shown in Fig. $1(c)$, total phosphorylase activity increased with total protein resulting in a constant specific activity of (mean \pm S.E.) $16 \cdot 3 \pm 1.2 \mathrm{nmol} \mathrm{min}^{-1}(\mathrm{mg}$ 


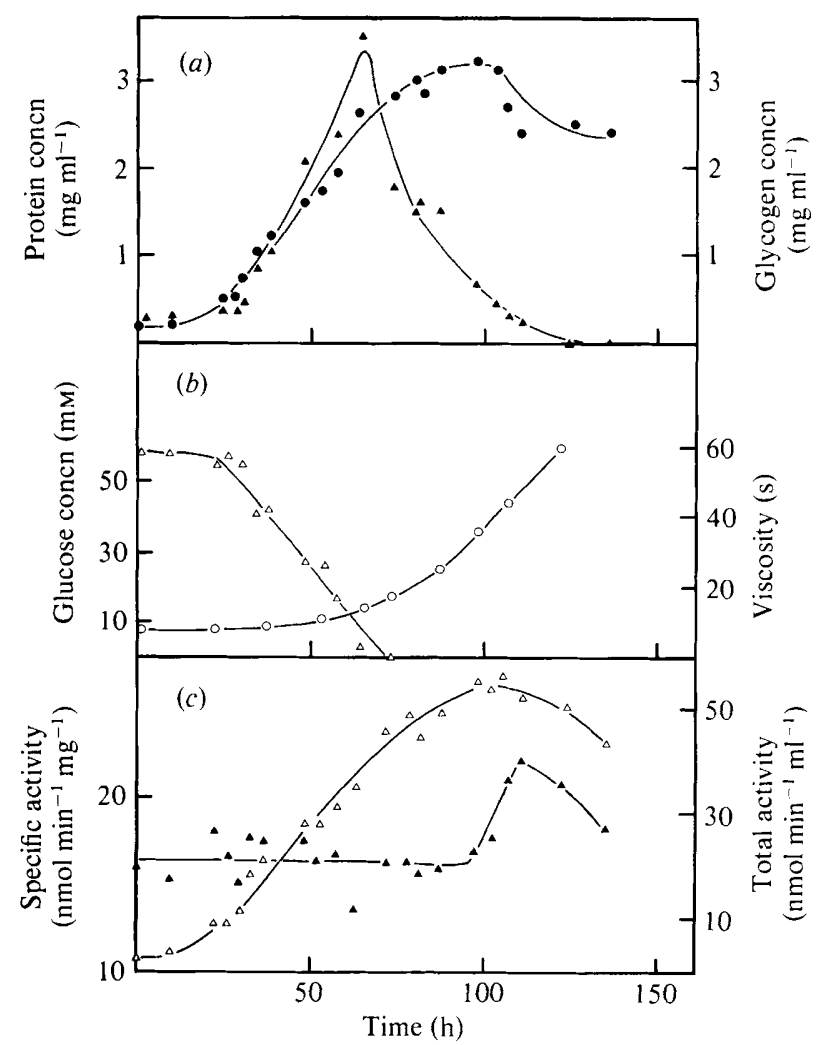

Fig. 1. Growth of Physarum polycephalum microplasmodia on axenic medium. (a) Glycogen ( $\mathbf{A}$ ) and protein $(\bigcirc)$ content of the plasmodia; $(b)$ glucose $(\triangle)$ and viscosity $(O)$ in the medium; $(c)$ glycogen phosphorylase activity in the plasmodia during growth, expressed as specific activity (mg plasmodial protein $)^{-1}(\mathbf{\Delta})$ and as total activity $(\mathrm{ml} \text { culture medium })^{-1}(\triangle)$.

protein $)^{-1}$. At the beginning of spherulation when glycogen was almost completely depleted, specific activity rose slightly, perhaps due to degradation of other proteins. This observation was corroborated by the measurement of phosphorylase specific activity during transition of microplasmodia to spherules (Fig. 2b) where specific activity increased from 16 to $20 \mathrm{nmol} \mathrm{min}-1$ (mg protein) $)^{-1}$ after $34 \mathrm{~h}$ of starvation when spherules first appeared.

Determination of specific activity in crude extracts alone does not give any information about a possible regulation by covalent modification as is observed in yeast (Becker, 1982). Enzyme concentration must also be determined. Monospecific antibodies against Physarum phosphorylase had been prepared (Nader, 1980), and phosphorylase concentration could therefore be estimated in crude extracts by the Laurell immunorocket method (Laurell, 1966). This assay was reliable only during spherulation (Fig. 2) because in the growth experiments the changing concentrations of protein interfered with the assay. The increase of phosphorylase specific activity during spherulation was matched by a corresponding increase of phosphorylase antigen fixing specific molecular activity at $24.3 \pm 3.4 \mu \mathrm{mol} \mathrm{min}^{-1}$ (mg phosphorylase) ${ }^{-1}$. Increase of specific activity, therefore, can be explained by a higher enzyme concentration and is not due to transition to a more active form.

\section{Glycogen degradation in axenic medium lacking either glucose or the nitrogen source}

In order to test whether endogenous factors or availability of external glucose govern depletion or synthesis of glycogen, cells were exposed to growth medium lacking either glucose or the nitrogen source. 


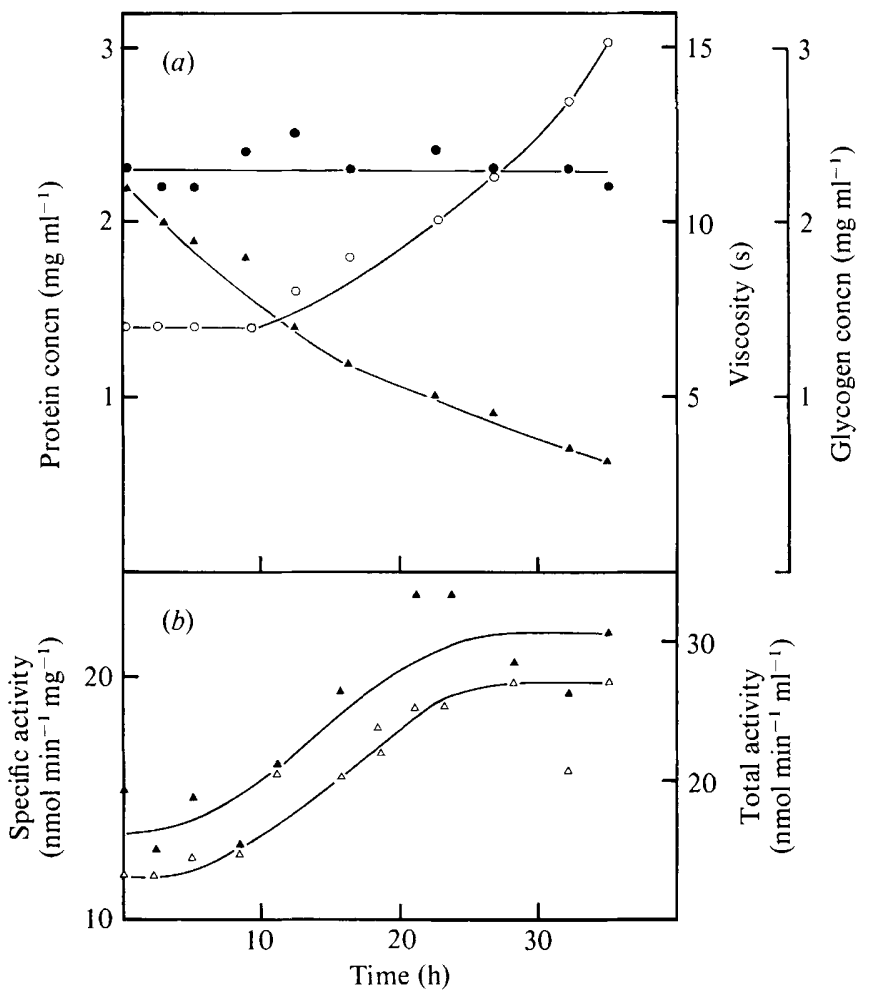

Fig. 2. Starvation of Physarum polycephalum plasmodia after transferring them into minimal medium. (a) Protein ( $)$ and glycogen $(\boldsymbol{\Lambda})$ in the plasmodia and viscosity $(O)$ in the medium; $(b)$ glycogen phosphorylase activity during starvation, expressed as specific activity $(\boldsymbol{\Lambda})$ and as total activity $(\triangle)$.

Plasmodia were grown in axenic medium for $48 \mathrm{~h}$ and then transferred into growth medium lacking glucose (Fig. 3a). Here the protein content increased during the first $25 \mathrm{~h}$, while glycogen was degraded immediately. Parallel to the glycogen breakdown the viscosity of the medium increased due to slime production.

Cells degrading glycogen (after $72 \mathrm{~h}$ of growth in axenic medium) were incubated in the presence of glucose without any nitrogen sources (Fig. $3 b$ ). Despite the availability of glucose, glycogen content initially remained constant and later slowly declined while slime was excreted. In contrast to the changes seen in complete medium, glucose was taken up very slowly, which might partially explain the lack of glycogen synthesis. Even after $2 \mathrm{~d}$, no spherules could be detected in this culture.

\section{Turnover of glycogen during growth}

The rapid loss of glycogen after removal of glucose despite the steady specific activity of glycogen phosphorylase may indicate a futile cycle of glycogen metabolism, in which glycogen is degraded while synthesis takes place. To test this possibility we measured the turnover rate of glycogen in growing plasmodia. The cells were grown on axenic medium with $\left[\mathrm{U}-{ }^{14} \mathrm{C}\right]$ glucose. After $72 \mathrm{~h}$, they were transferred into fresh medium with unlabelled glucose. As shown in Fig. 4, plasmodia start growing again with the protein content doubling in $30 \mathrm{~h}$ and glycogen content doubling in $20 \mathrm{~h}$. At the same time the ${ }^{14} \mathrm{C}$-labelled glycogen was degraded with a half life of $28 \mathrm{~h}$ (Fig. $4 b$ ). After $28 \mathrm{~h}$, glucose was depleted (Fig. $4 a$ ) leading to a net degradation of glycogen. Total glycogen was degraded faster than the labelled glycogen, suggesting that newly synthesized polyglucan chains from unlabelled glucose were degraded first, leaving the core of the glycogen synthesized from $\left[{ }^{14} \mathrm{C}\right]$ glucose relatively unchanged. Similar results were obtained in experiments with plasmodia, which were transferred into medium with unlabelled glucose after 38 and $48 \mathrm{~h}$ of growth on radioactive glucose. 


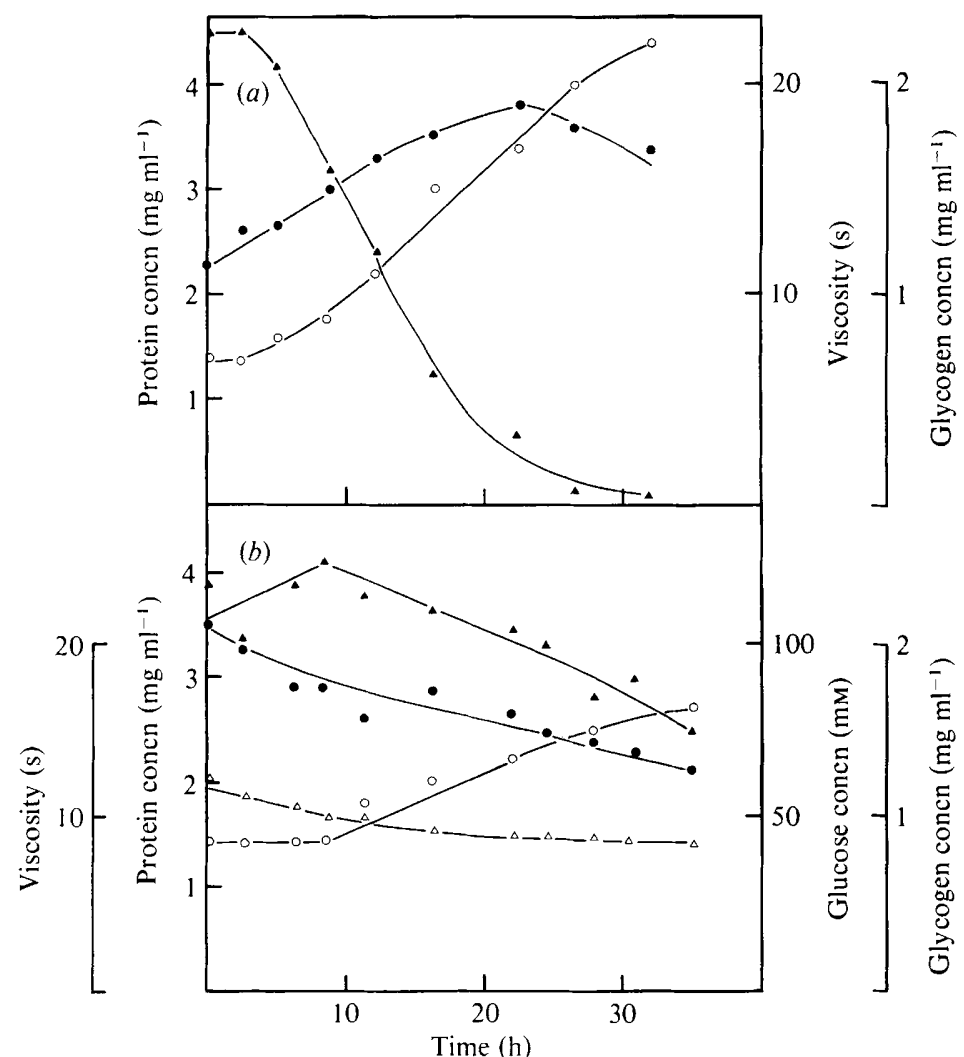

Fig. 3. Glycogen metabolism of Physarum polycephalum plasmodia after transferring them into medium without glucose or without nitrogen sources. (a) Protein $(\boldsymbol{O})$ and glycogen $(\boldsymbol{\Delta})$ in plasmodia in an axenic medium without glucose, and viscosity $(\bigcirc)$ of the medium; $(b)$ protein $(\boldsymbol{O})$ and glycogen $(\boldsymbol{\Lambda})$ in plasmodia in an axenic medium without nitrogen sources (tryptone and yeast extract), and viscosity $(\bigcirc)$ and glucose $(\triangle)$ in the medium.

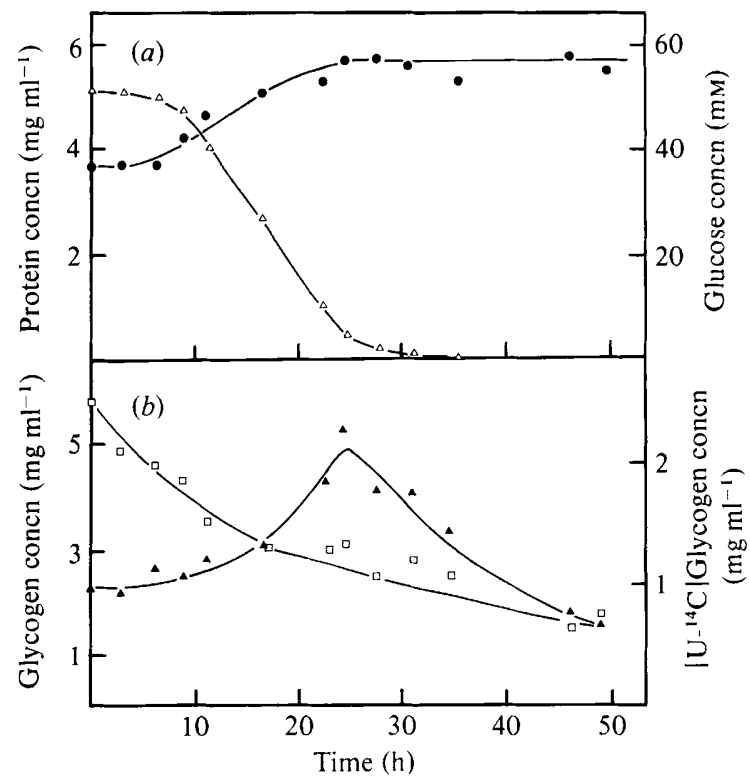

Fig. 4. Turnover of glycogen in growing Physarum polycephalum plasmodia. Microplasmodia, growing in an axenic medium with $\left[{ }^{14} \mathrm{C}\right]$ glucose, were transferred into a medium with unlabelled glucose. $(a)$ Protein ( $)$ in the plasmodia and glucose $(\triangle)$ in the medium; $(b)$ radioactive glycogen $(\square)$ and total glycogen $(\mathbf{A})$ in the plasmodia. 


\section{DISCUSSION}

Glycogen metabolism in microplasmodia of Physarum polycephalum responds most strongly to the availability of external glucose. Glycogen is always degraded as soon as exogenous glucose is consumed or removed, for example by transfer to spherulation medium. On the other hand, presence of glucose leads to glycogen synthesis only if nitrogen sources are available as well. This may be due to an inhibition of glucose uptake, which was also very low in the absence of nitrogen sources.

Degradation of glycogen was coupled to slime production as indicated by increase in viscosity as previously reported by McCormick et al. (1971).

Most surprisingly, glycogen metabolism was not sufficiently regulated, since during net glycogen synthesis a remarkable breakdown of glycogen occurred, indicating a futile cycle. In yeast, in contrast, glycogen degradation is switched off as soon as synthesis starts (Becker, 1982).

The changes in glycogen metabolism are compatible with the rather simple regulatory mechanisms of glycogen phosphorylase found in vitro (Nader \& Becker, 1979). The enzyme is constitutive and constitutes a relatively constant fraction of the total protein during growth and spherulation. This allows plasmodia of all growth phases to break down their glycogen as soon as glucose is removed. No drastic changes in specific activity and specific molecular activity were observed, corroborating the in vitro observation of the lack of modulation of enzyme activity by reversible phosphorylation (Nader \& Becker, 1979) at all stages of development of the plasmodia.

The enzyme activities measured in the extract are compatible with the glycogen degradation rates measured in vivo. The breakdown rates can be explained without additional amylase activity, necessary for glycogen breakdown, as postulated in Dictyostelium discoideum (Hames \& Ashworth, 1974).

The authors are indebted to Professor A. Betz, in whose laboratory the work was done, for support and discussion. We further thank Professor A. Hüttermann for critical ideas.

\section{REFERENCES}

BECKER, J. U. (1982). Mechanisms of regulation of glycogen phosphorylase activity in Saccharomyces carlsbergensis. Journal of General Microbiology 128, 447-454.

Becker, J. U., Shehata, M. J. \& Mizani, S. M. (1982). Influence of nitrogen sources on glycogen metabolism in Saccharomyces carlsbergensis. Journal of General Microbiology 128, 455-461.

BERGMEYER, H. U. (1974). Methoden der enzymatischen Analyse, vol. 1, pp. 1241-1250, Weinheim: Verlag Chemie.

Chen, G. S. \& Segel, I. H. (1968a). Escherichia coli polyglucose phosphorylases. Archives of Biochemistry and Biophysics 127, 164-174.

Chen, G. S. \& Segel, I. H. (1968b). Purification and properties of glycogen phosphorylase from Escherichia coli. Archives of Biochemistry and Biophysics 127, 175-186.

Daniel, J. W. \& Baldwin, H. H. (1964). Methods of culture for plasmodial myxomycetes. Methods in Cell Physiology 1, 9-41.

Fosset, M., Muir, L. W., Nielsen, L. D. \& Fischer, E. H. (1971). Purification and properties of yeast glycogen phosphorylase $a$ and $b$. Biochemistry 10, 4105-4113.

Goodman, E. M. (1980). Physarum polycephalum: a review of a model system using a structure-function approach. International Review of Cytology 63, 1-58.

Hames, B. D. \& Ashworth, J. M. (1974). The metabolism of macromolecules during the differentiation of the cellular slime mold Dictyostelium discoideum containing different amounts of glycogen. Biochemical Journal 142, 301-315.

HoffmanN, W. \& HüttermanN, A. (1975). Aminopeptidases of Physarum polycephalum. Activity, isoenzyme pattern and synthesis during differentiation. Journal of Biological Chemistry 250, 74207427.

HürtermanN, A. (1972). Isoenzyme pattern and de novo synthesis of phosphodiesterase during differentiation (spherulation) in Physarum polycephalum. Archives of Microbiology 83, 155-164.

LAURELL, C. B. (1966). Quantitative estimation of proteins by electrophoresis in agarose gels containing antibodies. Analytical Biochemistry 15, 45-53.

McCormick, J. J., Blomquist, J. C. \& Rusch, H. P. (1970). Isolation and characterization of an extracellular polysaccharide from Physarum polycephalum. Journal of Bacteriology 104, 1110-1118.

NADER, W. F. (1980). Glykogenstoffwechsel in Physarum polycephalum. Ph.D. thesis, University of Bonn, F.R.G.

NADER, W. F. \& BECKER, J. U. (1979), 1,4- $\alpha$-glucan phosphorylase from the slime mold Physarum polycephalum. European Journal of Biochemistry 102, 345355.

Thomas, D. A. \& Wright, B. E. (1976a). Glycogen phosphorylase from Dictyostelium discoideum: purifi- 
cation and properties of the enzyme. Journal of Biological Chemistry 251, 1253-1257.

Thomas, D. A. \& WRIGHT, B. E. (1976b). Glycogen phosphorylase from Dictyostelium discoideum: synthesis and degradation during differentiation. Journal of Biological Chemistry 251, 1258-1263.
Wright, B. E. \& Park, D. J. M. (1975). An analysis of the kinetic positions held by five enzymes of carbohydrate metabolism in Dictyostelium discoideum. Journal of Biological Chemistry 250, 22192226. 